\begin{tabular}{|c|l|}
\hline Title & $\begin{array}{l}\text { Three types of proteinases in Japanese common squid Todarodes pacificus hepatopancreas as studied by using carp } \\
\text { myofibrils as substrate }\end{array}$ \\
\hline Author(s) & Tian, Y uanyong; U mezawa, Emi; Duan, Rui; Konno, Kunihiko \\
\hline Citation & $\begin{array}{l}\text { Fisheries Science, 76(2), 365-373 } \\
\text { https://doi.org/10.1007/312562-009-0206-x }\end{array}$ \\
\hline Issue Date & 2010-03 \\
\hline Doc URL & http://hdl.handle.net/2115/43064 \\
\hline Rights & The original publication is available at www.springerlink.com \\
\hline Type & article (author version) \\
\hline File Information & FS76-2_365-373.pdf \\
\hline
\end{tabular}

Instructions for use 


\title{
Three types of proteinase in Japanese common squid Todarodes pacificus hepatopancreas as studied by using carp myofibrils as substrate
}

\author{
Yuanyong Tian ${ }^{\mathrm{a}}$, Emi Umezawa ${ }^{\mathrm{a}}$, Rui Duan ${ }^{\mathrm{b}}$, and Kunihiko Konno ${ }^{\mathbf{a}^{*}}$ \\ ${ }^{a}$ Faculty of Fisheries Sciences, Hokkaido University, Hakodate, Hokkaido 041-8611, Japan \\ b School of Marine Science and Technology, Huaihai Institute of Technology, Lianyungang 222005, China \\ *Corresponding author \\ Kunihiko Konno \\ E-mail: konnno@fish.hokudai.ac.jp
}


Abstract Three types of proteinases, namely cystein-, metallo-, and serine-proteinases were found in squid hepatopancreas by studying the inhibition spectra using carp myofibril as substrates. Cystein-, metallo-, and serine-type showed the highest activities at $50{ }^{\circ} \mathrm{C}, 35^{\circ} \mathrm{C}$, and $40{ }^{\circ} \mathrm{C}$, respectively. The optimal pHs were $\mathrm{pH}$ 5, $\mathrm{pH}$ 7, and $\mathrm{pH} 9$ for cystein-, metallo-, and serine-type, respectively. When assayed at $20^{\circ} \mathrm{C}$ and $\mathrm{pH} 7.5$, metallo-type showed the highest activity. Metallo-type was characterized by a high selectivity in the digestion of myosin. Among the three enzymes, cystein-type was found to be the most stable against thermal and acid treatments. Heat treated myofibrils were more susceptible to cystein- and serine-types, but less susceptible to metallo-type. Acid treatment of myofibrils also enhanced the digestibility by cystein-type. The results indicated that cystein-type seemed to be the most suitable enzyme to produce peptides from denatured myofibrils by their random digestion.

Keywords cystein-proteinase; denaturation; hepatopancreas; Japanese common squid; myofibrils; proteinase 


\section{Introduction}

Japanese common squid Todarodes pacificus is one of the most important marine resources as fishery industry in Japan, especially in Hakodate, Hokkaido. Mantle, fin, and leg parts are consumed as food, but viscera (hepatopancreas) mainly liver is usually discarded as an industry waste. Indeed squid liver is the essential component to produce fermented squid meat "Shiokara", the amount is negligible compared to total amount to be handled. It is well known that squid hepatopancreas contains several types of enzyme with high proteolytic activity [1, 2]. These enzymes have a potential to be used in food processing or to produce useful polypeptides. One of the successful applications of the high activity of these enzymes was a rapid fermentation of fish sauce [3]. Proteinases found in squid liver are metallo-proteinase [4-7], cystine-proteinase [8-10], serine-proteinase [11] and cathepsin D-like cystein-proteinase [12]. The information on the properties of proteinases in squid liver was accumulated, but many papers handled a single enzyme contained in the organ and there is little information on the contribution of respective enzymes in the activity of whole enzymes contained in liver. Moreover, their activity was mainly assayed by using synthetic substrate or model protein, such as casein or azocasein, as the substrate for activity assay because of convenience and easiness. Fishery waste such as fish bone or head still contains meat attached to them. They might be a good resource for producing marine polypeptides. When one tries to utilize the enzyme for the purpose, it is essential to identify the type of proteinase and to characterize their properties by using practical substrate. Therefore, we used myofibrils as a model substrate. Moreover, it seemed important to study whether their digestibility is affected by the denaturation of muscle protein because sometimes heated fishery waste would be the starting material for digestion. First, types of proteinases found in squid liver were characterized by using inhibition spectra with well characterized inhibitors. Then, digestion profiles of myofibrils by the respective enzymes in squid liver and their digestion rates were compared. Temperature and $\mathrm{pH}$ dependent activities of the enzymes were also studied. Their thermal and $\mathrm{pH}$ stabilities which are important factors in their utilization were also compared. Finally, effect of myofibril denaturation caused by heating and $\mathrm{pH}$ treatment on their digestion was studied. 


\section{Materials and methods}

Materials

Japanese common squid

Japanese common squids caught near Hakodate, Hokkaido, on the day of the experiment were attained from a local fish market. The whole livers (hepatopancreas) were removed from the squids and used for the experiment.

\section{Common carp Cyprinus Carpio}

Live carp cultured near Hakodate, were sent to the laboratory. The fish was sacrificed by beheading and its dorsal white muscle was taken. The minced meat was mixed with $10 \%$ sorbitol to prevent myosin denaturation, and then stored at $-40{ }^{\circ} \mathrm{C}$ until used.

Methods

Preparation of myofibrils

Myofibrils were prepared from the above frozen muscle of carp by using the method described by Kato and Konno [13] by repeated homogenization and washing in $0.1 \mathrm{M} \mathrm{NaCl} 20 \mathrm{mM}$ Tris- $\mathrm{HCl}$ (pH7.5). Myofibril suspension was then filtered through two layers of cotton gauze and the filtrate was used as myofibrils in the study.

Preparation of crude proteinases from squid liver 
Squid liver (about $5 \mathrm{~g}$, wet weight) in 10 volumes $0.1 \mathrm{M} \mathrm{NaCl} 20 \mathrm{mM}$ Tris-HCl (pH7.5) was homogenized by Polytron PT 3100 (Kinematica AG, Littau Switzerland) at 12,000 rpm for 30 sec 4 times in iced water. The homogenate was left for $30 \mathrm{~min}$ on ice, and centrifuged at $10,000 \mathrm{xg}$ for 20 min at $4{ }^{\circ} \mathrm{C}$ to recover the crude extract in the supernatant. After centrifugation of the homogenate, floating lipid layer on the surface of the aqueous solution was removed by sucking. A clear aqueous layer was taken as the enzyme extract. The extract was dialyzed against the above buffer overnight, and the dialyzate was used as crude proteinases preparation. Protein concentration was determined by using the modified Biuret method [14, 15].

Proteinase Activity Assay

Proteinase activity was studied by monitoring the degradation profiles of myofibrillar proteins using myofibril as substrates. Basic conditions for the assay were $0.5 \mathrm{M} \mathrm{NaCl}, 20 \mathrm{mM}$ Tris- $\mathrm{HCl}$ (pH7.5) with 2.5 $\mathrm{mg} / \mathrm{ml}$ of myofibrils in $200 \mu \mathrm{l}$ reaction mixture, namely dissolved myofibrils were used to make an assay easier. It is well known that optimal $\mathrm{pH}$ and temperature differed from enzyme to enzyme. However, as the first attempt, we studied the activity at the above conditions. Temperature of $20{ }^{\circ} \mathrm{C}$ was used so as not to denature myofibrils used as substrate as well as enzyme. The amount of crude enzyme to be added was properly chosen to have a suitable degradation of the myosin in myofibrils. For studying the inhibition spectrum, $30 \mu \mathrm{l}$ of inhibitors was also added into the reaction medium. $\mathrm{pH}$ and temperature for the reaction were optionally changed to study the optimal $\mathrm{pH}$ and temperature. In some experiments, heated or acid-, alkali-treated myofibrils were employed to study the effect of protein denaturation on the digestion. Myofibrils dissolved in $0.5 \mathrm{M} \mathrm{NaCl}$, pH 7.5 were heated at various temperatures for 30 min or were incubated at various $\mathrm{pH}$ for $2 \mathrm{~h}$ on ice. After treatment, $\mathrm{pH}$ of the solutions was adjusted to $\mathrm{pH} 7$ by adding either $1 \mathrm{M} \mathrm{NaOH}$ or $\mathrm{HCl}$. The enzyme reaction was stopped by adding $0.3 \mathrm{ml}$ of solution consisted of $8 \mathrm{M}$ urea, 2 \% SDS, 2 \% 2-mercaptoethanol, and 20 mM Tris-HCl (pH 7.5) (SDSUM solution) accompanied by an immediate boiling for $1 \mathrm{~min}$. The digests were subjected to SDS-PAGE (7.5\% polyacrylamide gel) [16] to analyze the degradation profile of myofibrillar protein, especially myosin. Protein bands separated on the 
gel were stained with Coomassie brilliant Blue R-250. Although myofibrils contained several protein components, we focused on the degradation of myosin because of its high content and the high susceptibility. Thus, disappearing rate of myosin heavy chain (MHC) revealed by SDS-PAGE was used to represent the activity of the enzymes. Logarithmic remaining MHC content was plotted against reaction time. The reaction rate was estimated from the slope of the straight line obtained. The specific activity was defined as the decrease in MHC content in 1 min by $1 \mathrm{mg}$ of crude enzyme used with myofibril concentration of 1 $\mathrm{mg} / \mathrm{ml}$. The staining intensity of MHC band on SDS-PAGE was measured by using Fuji Film Multi Gauge 2.0 system (Fujifilm Co. Tokyo, Japan) after the scanning of the gel on CanoScan 8000F (Canon Co. Tokyo Japan).

Identification of the proteinase in crude enzyme by using various types of proteinase inhibitors

To characterize the type of proteinase in the crude enzyme, inhibition spectrum of the enzyme activity was studied. The inhibitors were as follows: E-64 $(10 \mu \mathrm{M})$, N-ethylmaleimide (NEM) (1 mM), p-chloromerculic benzoate (pCMB) $(5 \mathrm{mM})$, leupeptin $(10 \mu \mathrm{M}), o$-phenanthroline (3 mM), EDTA (5 mM), phenylmethylsulfonyl fluoride (PMSF) (1 mM), soybean trypsin inhibitor (SBTI) (100 $\mu \mathrm{g} / \mathrm{ml})$, and pepstatin (10 $\mu \mathrm{g} / \mathrm{ml})$. o-phenanthroline, EDTA, and PMSF were purchased from Wako Pure Chemicals (Osaka, Japan), and E-64, NEM, pCMB, leupeptin, SBTI and pepstatin were from Sigma-Aldrich (St Louis, USA). The inhibitors were added separately or in various combinations. We confirmed that the concentrations of the respective inhibitors were high enough to inhibit the specific enzyme almost completely by studying concentration dependent inhibition.

All of the experiments were repeated separately at least three times, and the results with high reproduction were presented instead of using statistic analysis of the data.

\section{Results}


Characterization of the proteinases present in crude extract from squid liver

The proteolytic activity was accessed by studying the digestion patterns of myofibrillar proteins on SDS-PAGE. The method could give the information on the degradation process of respective proteins in myofibrils. The crude enzyme degraded myosin and actin quite steadily (see Fig. 1). Degradation rate, as defined as the disappearing rate of MHC from the SDS-PAGE pattern, was proportional to the amount of enzymes used. Therefore, the quantitative analysis of the activity became possible (data not shown).

First, types of proteinase in the extract were identified by studying the inhibition spectrum. The digestion conditions were $0.5 \mathrm{M} \mathrm{NaCl}, 20 \mathrm{mM}$ Tris- $\mathrm{HCl} \mathrm{pH} 7.5$ at $20^{\circ} \mathrm{C}$, where myofibrils were dissolved and no denaturation was assumed. When digested without any inhibitors, MHC and actin band were degraded into fragments upon incubation with the extract (see Fig.1, lane (a)). Then, the reaction was carried out in the presence of various types of proteinase inhibitors at the concentrations as described in the Materials and Methods section. Although the data were not presented, E-64, leupeptin, pCMB, NEM, SBTI, PMSF, EDTA, and $o$ - phenanthroline showed the inhibitory effects more or less as detected by high content of remaining MHC. It was indicated that crude extract contained at least three types of proteinases, cystein-, metallo-, and serine-proteinases within. Since pepstatin did not show any inhibitory effect, the extract practically did not contain pepsin-like protease.

Fig. 1 showed the SDS-PAGE patterns of the myofibril digested by the crude extract from squid liver in the absence or presence of various combinations of the inhibitors. As shown in Fig. 1a, almost all of MHC disappeared and several fragments migrating between MHC and actin were detected. Numerous numbers of fragments with various sizes were seen in the digest under the employed conditions. Decreased staining density of actin band upon incubation indicated its degradation by the enzymes in the extract. The degradation of myosin and actin was almost completely suppressed upon addition of the mixture of above three inhibitors (Fig. 1e). Indeed, a very slight amount of degraded fragments was detectable in the pattern the amount was negligible to study the digestion pattern of myofibrils by the respective enzymes. It is also confirmed that the concentrations of inhibitor employed were practically sufficiently high to inhibit 
respective enzymes. It became possible to study the digestion pattern by a single enzyme in the extract by inhibiting the others. For example, metallo-proteinase activity could be measured by adding E-64 and PMSF to inhibit cystein- and serine-types, respectively. The digestion patterns of myofibrils by respective proteinases were compared (Fig. 1). Metallo-type produced specific fragments from myosin migrating between MHC and actin band. No product below actin was seen (Fig. 1b). The pattern was the reproduction of the results by Tamori et al. [7]. According to them, the 150 kilodalton (kDa), $140 \mathrm{kDa}$, and $110 \mathrm{kDa}$ are the fragments coming from heavy meromyosin and other three (50 kDa, $60 \mathrm{kDa}$, and $90 \mathrm{kDa}$ ) are their counterparts, light meromyosin. No degradation of actin and tropomyosin was seen. Thus, metallo-type enzyme was characterized by the selective digestion of MHC at the limited sites under the conditions. Fragments detected in the digest without inhibitors (Fig. 1a) were the same as ones found in the digests by the metallo-type alone. Less amount of the fragments detected in the digest without inhibitors indicated their further digestion by other proteinases. Under the same conditions, cystein-type, in the presence of o-phenanthroline and PMSF, produced a band (135 kDa) together with numerous bands distributed throughout the lane (Fig. 1c). Cystein-proteinase seemed to digest myosin and actin at numerous sites. Bands migrating below myosin light chain indicated the cleavage of myosin and actin into very short fragments. The enzyme contributed to the reduced amount of actin band in the digest without inhibitors. The digestive ability of serine-proteinase was very low, producing a faint band (170 kDa) (Fig. 1d). Its contribution to the digestion of myofibrils by the crude enzyme seemed the least.

Myofibrils were incubated at $20^{\circ} \mathrm{C}$ with crude extract in the presence of a mixture of two inhibitors in the reaction medium containing $0.5 \mathrm{M} \mathrm{NaCl}, 20 \mathrm{mM}$ Tris- $\mathrm{HCl} \mathrm{pH}$ 7.5. As shown in Fig. 2, plotting of logarithmic remaining MHC content against incubation time gave straight lines for all proteinases with different slopes. The rate was calculated from the slope of the line by considering enzyme and myofibrils concentrations. Metallo-type showed the largest rate, cystein-type followed, and the rate of serine-type was very small. When the activity of metallo-type was taken as 1.0, those of cystein- and serine-types were 0.14 and 0.04 , respectively. 
Effect of temperature on the activities

The optimal temperatures for three enzymes were compared (Fig. 3). The rates obtained at various temperatures were analyzed by using Arrhenius' equation. Activities for all three enzymes increased with raising the reaction temperature and inactivation was obvious at high temperatures. The maximal temperatures for cystein-, metallo-, and serine-types were obtained at 50 , 35 , and $40{ }^{\circ} \mathrm{C}$, respectively. Therefore, cystein-type seemed the most stable among the three. Activities at low temperature range gave straight lines for all of the proteinases. Cystein-type showed the steepest slope with activation energy of 41.8 $\mathrm{kcal} / \mathrm{mol}$, while the other two had the similar values of $23.7 \mathrm{kcal} / \mathrm{mol}$. Although metallo-type showed the highest activity at low temperature range around $20-30{ }^{\circ} \mathrm{C}$, cystein-type showed the highest activity above 35 ${ }^{\circ} \mathrm{C}$ due to its high activation energy and its stable nature under the conditions. Serine-proteinase always showed the lowest activity at all temperatures.

Thermal stability of the three proteinases

Cystein-proteinase was suggested to be the most thermostable among the three enzymes by studying the temperature dependent activities. We also studied their thermal stabilities. The crude enzyme containing the three types was heated for 30 min at various temperatures from 20 to $60{ }^{\circ} \mathrm{C}$, and relative remaining activities of three types were separately measured in the presence of combinations of two inhibitors as described in Fig. 1 . The activities of metallo- and serine-types began to decrease upon heating at $30{ }^{\circ} \mathrm{C}$, while that of cystein-type began to drop at $35^{\circ} \mathrm{C}$ (Fig. 4.) Thus, cystein-type was the most resistant against heating. Half inactivation temperatures for cystein-, metallo-, and serine-type enzymes were $44{ }^{\circ} \mathrm{C}, 40{ }^{\circ} \mathrm{C}$ and $35{ }^{\circ} \mathrm{C}$, respectively. It was notable that although cystein-type was the most stable, its inactivation occurred above 35 ${ }^{\circ} \mathrm{C}$, while the enzyme had the highest activity at $50{ }^{\circ} \mathrm{C}$ (Fig. 3) and heating at $50{ }^{\circ} \mathrm{C}$ for 30 min inactivated cystein-type significantly (Fig. 4). This was true for other two types of enzymes. Metallo-type showed lower maximal temperature $\left(35^{\circ} \mathrm{C}\right)$ than serine-type $\left(40^{\circ} \mathrm{C}\right)$ in Fig. 3, but thermal stability of the former was better than the latter. 
Effect of thermal treatment of myofibrils on the proteinase activity

The activities at high temperatures in Fig. 3 included three factors; effect on the proteinase activity itself, inactivation of the enzyme, and the denaturation of myofibrillar proteins, especially myosin. Structural change of protein is usually accompanied by the change in the proteinase activity. Thus, the effect of myosin denaturation on the activity was examined. Myofibrils dissolved in $0.5 \mathrm{M} \mathrm{NaCl}, 20 \mathrm{mM}$ Tris- $\mathrm{HCl}(\mathrm{pH} 7.5)$ were heated at various temperatures and were digested at $20{ }^{\circ} \mathrm{C}$ with three types of enzyme (Fig. 5). Heating myofibrils up to $30{ }^{\circ} \mathrm{C}$ did not change the activities of three enzymes. Changes in the rate were obvious between 30 and $50{ }^{\circ} \mathrm{C}$, but the effect was enzyme-dependent. The rate for metallo-type decreased to half when heated myofibrils above $50{ }^{\circ} \mathrm{C}$ were used. In contrast, cystein-type showed a low activity with unheated myosin, but its activity was significantly enhanced upon heating of myofibrils above $50{ }^{\circ} \mathrm{C}$. The acceleration of the activity upon heating of myofibrils was about 8 times. The activity of serine-type was also enhanced upon heating of myofibrils like cystein-type, but the enhancement achieved was only 3.5 times. Raising temperature even to $100{ }^{\circ} \mathrm{C}$ did not give additional effect. These results characterized three types of enzyme; the same structural changes occurring in myosin molecule resulted in different consequences for three types of proteinase. Myofibrils became less sensitive to metallo-type, but more sensitive to cystein- and serine-types. Cystein-type showed the highest activity when heated myofibrils were the substrate even at low temperature of $20^{\circ} \mathrm{C}$. The activity of serine-proteinase was still the lowest although the digestibility increased upon heating of myofibrils.

We compared the digestion profiles of heated myofibrils with ones of control myofibrils by three types of enzyme. Heated myofibrils at $50{ }^{\circ} \mathrm{C}$ for 30 min were employed. When digested by cystein-type (Fig. 6), control myofibrils produced 135 kDa fragment (Fig. 6a), but MHC in heated myofibrils disappeared quickly producing numerous umbers of fragments (Fig. 6b). Although several clear bands were seen in an early phase of digestion, such bands disappeared in a latter phase indicating thier further digestion into much short fragments. The fact suggested an increased cleavage sites on myosin as a result of denaturation upon heating 
of myofibrils. Moreover, disappearance of actin band also characterized the pattern indicating an increased susceptibility of denatured actin in heated myofibrils. A similar change in the pattern by serine-proteinase was observed. The fragments produced from the heated myofibrils by metallo-type were indistinguishable from ones from control myofibrils, but the amounts were less (patterns not shown). We again studied the temperature dependent activities with heated myofibrils $\left(50^{\circ} \mathrm{C}, 30 \mathrm{~min}\right)$. The maximal temperatures were 50 ${ }^{\circ} \mathrm{C}$ for cystein-type, $35{ }^{\circ} \mathrm{C}$ for metallo-type, and $40^{\circ} \mathrm{C}$ for serine-type, which are the same as obtained with unheated samples (data not shown).

Effect of $\mathrm{pH}$ on the activity

To characterize the three types of enzymes, $\mathrm{pH}$ dependent activities were measured at $20{ }^{\circ} \mathrm{C}$ (Fig. 7). Metallo-type showed a quite high activity at around $\mathrm{pH}$ 7, and the activity dropped steeply by shifting the $\mathrm{pH}$ to acidic or alkaline range. The activity at $\mathrm{pH} 5$ was negligible and one at $\mathrm{pH} 10$ was only $16 \%$ of that at $\mathrm{pH}$ 7. The maximal activity was obtained at $\mathrm{pH} 5$ for cystein-type and the activity at $\mathrm{pH} 7$ was roughly $20 \%$ of that at $\mathrm{pH}$ 5. The activity was no longer detectable above $\mathrm{pH}$ 8. High activity of cystein-proteinase at acidic conditions suggested that the enzyme belongs to cathepsin family. Serine-proteinase gave the optimal $\mathrm{pH}$ at $\mathrm{pH}$ 9. Activity at $\mathrm{pH} 7$ was about $65 \%$ that at $\mathrm{pH} 9$, and the activity below $\mathrm{pH} 6$ was negligible.

pH stability of three proteinases

As three types of proteinase showed different thermal stabilities, their $\mathrm{pH}$ stability was further compared. Enzyme solution was incubated at various $\mathrm{pH}$ for $2 \mathrm{~h}$ on ice and remaining relative activities were measured at $\mathrm{pH} 7.0$ and $20^{\circ} \mathrm{C}$ after neutralization of enzyme solution (Fig. 8). The $\mathrm{pH}$ used for the assay was not the optimal one for cystein- and serine-types, but the conditions were chosen to eliminate the effect of denaturation of myofibrils by $\mathrm{pH}$ shifting on the activity as will be described later. All of three enzymes were quite stable at neutral pH and an inactivation occurred at acidic and alkaline pH ranges, showing bell shaped graphs. Treatment at pH 3 slightly inactivated the activity of cystein-type giving an activity of $90 \%$, while 
the inactivation of metallo- and serine-types was remarkable showing relative remaining activities of $23 \%$ and $55 \%$, respectively. Treatment at pH 10 also inactivated the three enzymes more or less. The remaining activities of cystein-, serine-, and metallo-types were 95, 95, and 72\%, respectively. Cystein-type showed the highest remaining activity after treatment at $\mathrm{pH} 3$ and $\mathrm{pH}$ 10, indicating that the enzyme was the most stable against acid or alkali treatments. Metallo-type was the most unstable under acidic region and serine-type was the most unstable at alkaline $\mathrm{pH}$ range.

Effect of acid and alkali-treatment of myofibril on its digestibility by the three proteinases

It is certain that incubation of proteins under acid or alkali conditions also denatures proteins. We wondered whether acid or alkali-treatment of myofibrils alters the digestibility by the enzymes. For the purpose, myofibrils were incubated at various $\mathrm{pH}$ from 3 to 10 for $2 \mathrm{~h}$ on ice. After treatment, the myofibril solution was neutralized with $1 \mathrm{M}$ Tris or $1 \mathrm{M} \mathrm{HCl}$. Thus treated myofibrils were digested at $20^{\circ} \mathrm{C}$ at $\mathrm{pH} 7.0$ (Fig. 9). Again, neutral $\mathrm{pH}$ for the assay was chosen to remove the effect of myofibril denaturation on the activity. It should be emphasized that the $\mathrm{pH}$ on the horizontal axis in Fig. 9 was $\mathrm{pH}$ for treatment of myofibrils not for assay. The activities measured with control myofibrils corresponded to ones at pH 7 in Fig. 9. Acid treatment of myofibrils decreased the metallo-type activity remarkably and the activity was around $20 \%$ when treated at $\mathrm{pH} 4$ or 3 . A similar suppressive effect was seen when myofibrils were treated at alkaline $\mathrm{pH}$ range. The activity with myofibrils treated at $\mathrm{pH} 10$ was roughly a half. On the other hand, cystein-type exhibited an accelerated activity upon acid treatment of myofibrils below $\mathrm{pH}$ 5. The increment of the activity by the treatment at $\mathrm{pH} 3$ was about 5 times. As the heating myofibrils accelerated about 8 times, the acid treatment gave a similar effect on the digestibility. However, alkali treatment of myofibrils did not enhance its activity at all. When compared the activities by using myofibrils treated at $\mathrm{pH} 3$, cystein-type showed the highest activity among the three (see the activities at pH 3 in Fig. 9). Acid treatemtn reduced the serine-type activity, which was different from the case of cystein-type. Since the heating of myofibrils enhanced the serine-proteinase activity like cystein-type, the structural changes in myosin 
molecule caused by acid treatment was different from that by heating for serine-type. Like cystein-type, alkali treatment of myofibrils unaffected the activity of serine-proteinase at all.

We compared the digestion patterns of untreated, alkali-treated ( $\mathrm{pH} 10)$, and acid-treated $(\mathrm{pH} 3)$ myofibrils by the three types of enzymes (data not shown). When acid treated myofibrils were digested with cystein-type, new bands appeared and MHC content decreased quickly. Actin in acid-treated myofibrils was more severely digested by the enzyme. However, the pattern obtained with alkali-treated myofibrils was almost the same as one obtained with untreated myofibrils. When metallo-type was used, both treatments at pH 3 and pH 10 suppressed the digestibility without changing the sizes of the fragments produced. These were the reproduction of the results as observed with heated myofibrils. Degradation of myosin by serine-proteinase was suppressed upon treatment at $\mathrm{pH} 3$, while the pattern with myofibrils treated at $\mathrm{pH} 10$ was rather similar to one obtained with control myofibrils. We studied the $\mathrm{pH}$ dependent activities of the three enzymes by using thermal or acid treated myofibrils. The profiles were the reproduction of the case of untreated myofibrils. The results included the effect of $\mathrm{pH}$ on myosin denaturation as well as on the activity.

\section{Discussion}

For studying the proteinase activity, casein is widely used as a substrate, and the production of acid-soluble peptides was often the index. In this paper, myofibrils as model substrate were employed to study the properties of proteinase in squid liver because we intend to degrade meat attached to fishery wastes with the enzymes as a practical application. In the application, whole enzymes without separation would be practical. Thus, the types of proteinase present in the crude extract were characterized. Finally, it was proved that metallo-, cystein-, and serine-proteinases were the three major enzymes. The conclusion was the confirmation of the previous results appeared in the separate papers [4-11]. Among the three, metallo-type was the most active at neutral $\mathrm{pH}$ with native myofibrils. However, different conclusion was made when denatured myofibrils by heating were the substrate; activity of cystein-type was significantly accelerated with the denatured myofibrils showing the highest activity. Acceleration was also observed with serine-type, 
but the extent was less. In contrast, the activity of metallo-type was suppressed with the denatured myofibrils. Increased digestibility of myofibrils upon heating was the consequence of the exposure of new cleavage sites on myosin molecule to cystein- and serine-types as observed in chymotryptic digestion of heated myofibrils [17]. However, the same structural change of myosin did not expose new cleavage sites for metallo-type, and rather suppressed. The suppression was explained by shielding of the selective cleavage sites by aggregate formation by denatured myosin because the fragmentation pattern of myosin by metallo-type unchanged upon heating of myofibrils. Basically the same conclusion was made with denatured myofibrils by acid-treatment. Denaturation by alkali-treatment gave a different effect from acid-treatment on the activities. Indeed, alkali-treatment of myofibrils suppressed the metallo-type activity as acid-treatment, the same treatment unaffected the digestibility by cystein-type. It is certain that alkaline treatment such as at $\mathrm{pH} 10$ denatures myosin showing a remarkable inactivation of myosin Ca-ATPase activity [20]. There are many reports on the denaturation of muscle protein at acidic region [18, 19], but little report on the alkali-denaturation. To understand the different consequence of alkali- and acid-treatment of myofibrils on the cystein-proteinase activity, a further study on myosin denaturation by alkali treatment is needed.

Three proteinases in squid liver were characterized by their different optimal $\mathrm{pH}$. The optimal $\mathrm{pH}$ at neutral $\mathrm{pH}$ for the metallo-type was in a good agreement with the result by Tajima et al. [5]. Cystein-type had an optimal $\mathrm{pH}$ at around 5, which was similar to one for cathepsin $\mathrm{L}$ extracted from jumbo squid hepatopancreas $[9,10]$. In their report, a slight different optimal $\mathrm{pH}$ was measured with azocasein (pH 5) and with synthetic substrate, z-PAAFC (pH 4.5). Aranishi [21] also reported that when Z-Phe-Arg7-amino-4-triflouro-methyl coumarin was used as substrate, the maximum activity was obtained at $50^{\circ} \mathrm{C}, \mathrm{pH}$ 5.5-6.0. Although there were small differences in the values between ours and theirs, general features of our enzyme resembled theirs. It was suggested that our cystein-type is a member of cathepsin family.

Among the three, cystein-proteinase was the most stable showing the highest maximal temperature of 50 ${ }^{\circ} \mathrm{C}$, which was a similar conclusion as the previous reports made; the optimal temperature for cystein-type extracted from jumbo squid hepatopancreas was $55{ }^{\circ} \mathrm{C}[9,10]$. A separate experiment of heating crude enzyme gave the same conclusion. 
Considering the following four factors, optimal $\mathrm{pH}$ and temperature, stability, and the state of myofibrils used, it was concluded that choosing the favorable conditions for cystein-type is the best way to degrade muscle protein in waste efficiently. Denatured meat probably by heating would be favorable starting material for digestion. The recommended conditions for degradation of meat are acidic $\mathrm{pH}$ such as $\mathrm{pH} 5$ and at high temperature such as $50{ }^{\circ} \mathrm{C}$ with denatured meat. When the raw fishery waste is the starting material, its cooking by boiling before digestion would improve the degradation rate. At the same time, the treatment surely removes unfavorable compounds such as fishy smell or lipid into hot water. Metallo-type seemed less useful for the production of severely degraded short peptides, but the enzyme would be useful to prepare active myosin fragments such as heavy meromyosin because the cleavage was very selective. Serine-type seemed practically useless due to its low activity.

In the present study, the extract from squid liver with a buffer was used as crude enzyme. Practically, a direct usage of liver itself for digesting proteins in waste would be easier and simpler. The research on this subject is now on going.

\section{References}

1. Hatate H, Tanaka R, Suzuki N, Hama Y (2000) Comparison of proteinase activity in liver among several species of squid and cuttlefish. Fish Sci 66:182-183

2. Makinodan Y, Nakagawa T, Hujita M (1993) Effect of cathepsins on textural change during ripening of Ika-shiokara (salted squid preserves). Nippon Suisan Gakkaishi. 59:1625-1629 (in Japanese with English abstract)

3. Raksakulthai N, Lee Y Z, Haard N F (1986) Effect of enzyme supplements on the production of fish sauce from male capelin Mallotus villosus. Food Sci Technol J 19:28-33

4. Okamoto Y, Otauka-Fuchino H, Horiuchi S, Tamiya T, Matsuraoto J J, Tsuchiya T (1993) Purification and characterization of two metalloproteinases from squid mantle muscle, myosinase I and myosinase II. Biochim Biophys Acta 1161:97-104 
5. Tajima T, Tamori J, Kanzawa N, Tamiya T, Tsuchiya T (1998) Distribution of myosinase I and myosinase II in tissues of Coleoidea. Fish Sci 64:808-811

6. Tsujioka E, Rhara T, Kanzawa N, Noguchi S, Tsuchiya T (2005) Effects of additives on the thermal gelation of Japanese common squid natural actomyosin. Fish Sci 71:688-690

7. Tamori J, Kanzawa N, Tajima T, Tamiya T, Tsuchiya T (1999) Purification and characterization of a novel isoform of myosinase from spear squid liver. J Biochem 126: 969-974

8. Sakai-Suzuki J, Tobe M, Tsuchiya T, Matsumoto J J (1986) Purification and characterization of acid cystein proteinase from squid mantle muscle. Comp Biochem Physiol 85B:887-893

9. Cardenas-Lopez J L, Haard N F (2005) Cystein proteinase activity in Jumbo squid Dosidicus gigas hepatopancreas extracts. J Food Biochem 29:171-186

10. Cardenas-Lopez J L, Haard N F (2009) Identification of a cystein proteinase from Jumbo squid Dosidicus gigas hepatopancreas as cathepsin L. Food Chem 112:442-447

11. Ebina H, Nagasbima Y, Ishizaki S, Taguchi T (1995) Myosin heavy chain-degrading proteinase from spear squid muscle. Food Res Int 28:31-36

12. Komai T, Kawabata C, Amanob M, Lee B R, Ichishima E (2004) Todarepsin, a new cathepsin D from hepatopancreas of Japanese common squid Todarodes pacificus. Comp Biochem Physiol 137 B:373-382

13. Kato S, Konno K (1993) Isolation of carp myosin rod and its structural stability. Nippon Suisan Gakkaishi 59:539-544 (in Japanese with English abstract)

14. Gomall A G, Bardawill C J, David M M (1949) Determination of serum proteins by means of the biuret reaction. J Biol Chem 177:751-766

15. Umemoto S (1966) A modified method for estimation of fish muscle protein by biuret method. Nippon Suisan Gakkaishi 32:427-35 (in Japanese with English abstract)

16. Laemmli U K (1970) Cleavage of structural proteins during assembly head of bacteriophage T4. Nature 277:680-685

17. Konno K, Yamamoto T, Takahashi M, Kato S (2000) Early structural changes in myosin rod upon 
heating of carp myofibrils. J Agric Food Chem 48:4905-4909

18. Funatsu Y, Arai K (1990) Acid-induced denaturation of carp myofibrillar protein. Nippon Suisan Gakkaishi 56: 2061-2067 (in Japanese with English abstract)

19. Hashimoto A, Arai K (1985) The effect of pH on the thermostability of fish myofibrils. Nippon Suisan Gakkaishi 51: 99-105 (in Japanese with English abstract)

20. Hashimoto A, Arai K (1978) The effect of $\mathrm{pH}$ and temperature on the stability of myofibrillar Ca-ATPase from some fish species. Nippon Suisan Gakkaishi 44:1389-1393 ～(in Japanese with English abstract)

21. Aranishi F, Ogata H, Hara K, Osatomi K, Ishihara T (1997) Purification and characterization of cathepsin L from hepatopancreas of carp Cyprinus carpio. Comp Biochem Physiol 118B:531-537 


\section{Figure captions:}

Fig. 1 Digestion patterns of carp myofibrils by three types of proteinases in squid liver

Carp myofibrils $(2.5 \mathrm{mg} / \mathrm{ml})$ were incubated with the crude enzymes extracted from squid liver for $1 \mathrm{hr}$ at $20^{\circ} \mathrm{C}$ in a medium consisting of $0.5 \mathrm{M} \mathrm{NaCl}, 20 \mathrm{mM}$ Tris- $\mathrm{HCl}$ (pH 7.5). To study the digestion patterns by the respective enzymes, the medium also contained inhibitors to inhibit rest of them. (a) without any inhibitors; (b) with E-64 and PMSF (metallo-type); (c) with o-phenanthrolin and PMSF (cystein-type); (d) with E-64 and o-phenanthrolin (serine-type); (e) with E-64, o-phenanthrolin and PMSF; (f) myofibrils without incubation. The concentrations of inhibitor used are $10 \mu \mathrm{M}, 1 \mathrm{mM}, 3 \mathrm{mM}$ for E-64, PMSF, and o-phenanthrolin, respectively. MHC, Actin, TM, TN-T, LC1, TN-I, LC2, and LC3 are myosin heavy chain, actin, tropomyosin, troponin-T, light chain 1, troponin-I, light chain 2, and light chain 3 component, respectively. Numbers with kDa show the molecular weight of the components as molecular weight makers.

Fig. 2 Estimation of digestion rates by proteinases

Myofibrils were digested under the same conditions with combinations of inhibitors as in Fig. 1. Decrease of MHC content was analyzed by applying the first order reaction; Logarithmic remaining MHC contents was plotted against incubation time. Metallo-type (with E-64 and PMSF, 口); cystein-type (with o-phenanthrolin and PMSF, o); serine-type (with E-64 and o-phenanthrolin $\triangle$ ).

Fig. 3 Temperature-dependent digestion rate of three types of proeinases

Activities of the respective three enzymes were estimated as in Fig. 2 and the rates at various temperatures were measured. The activities were analyzed by using Arrhenius plot. The same symbols as in Fig. 2 were used.

Fig. 4 Thermal stability of three types of proteinases 
The crude extract dissolved in $0.1 \mathrm{M} \mathrm{NaCl}, 20 \mathrm{mM}$ Tris- $\mathrm{HCl}(\mathrm{pH}$ 7.5) was heated for $30 \mathrm{~min}$ at various temperatures. Activities of three types of proteinase were assayed as in Fig. 1 inhibiting the other two enzymes by adding specific inhibitors. Remaining relative activities were plotted against heating temperature. The same symbols as in Fig. 2 were used.

Fig. 5 Effect of thermal treatment of myofibrils on the activities of three types of proteinases Myofibrils in $0.5 \mathrm{M} \mathrm{NaCl}, 20 \mathrm{mM}$ Tris- $\mathrm{HCl}(\mathrm{pH}$ 7.5) were heated for $30 \mathrm{~min}$ at various temperatures except at $100^{\circ} \mathrm{C}$ (2 min). By using these myofibrils, activities of three types of proteinsas were assayed at $20^{\circ} \mathrm{C}, \mathrm{pH}$ 7.0. Other conditions for assay and symbols are the same as in Fig. 2.

Fig. 6. Comparison of the digestion patterns of control and heated myofibrils by cystein-type Control myofibrils (a) and myofibrils heated for $30 \mathrm{~min}$ at $50^{\circ} \mathrm{C}$ (b) were digested in the presence of o-phenanthrolin and PMSF to study the digestion by cystein-proteinase. Other conditions were the same as in Fig. 1.

Fig. $7 \mathrm{pH}$ dependent activities of three types of proteinases

The digestion rates were measured by changing $\mathrm{pH}$ of the reaction medium. Other conditions for assay were the same as in Fig. 2. The same symbols as in Fig. 2 were used.

Fig. $8 \mathrm{pH}$ stability of three types of proteinases

The crude extract in $0.5 \mathrm{M} \mathrm{NaCl}, 20 \mathrm{mM}$ Tris- $\mathrm{HCl}(\mathrm{pH} 7.5)$ was incubated for $2 \mathrm{~h}$ in ice-cold water at various $\mathrm{pH}$ and neutralized. Remaining activities of three types of proteinases in the treated enzyme solutions were assayed and relative activities were plotted as in Fig. 3. The same symbols as in Fig. 2 were used.

Fig. 9 Effect of acid- and alkali-treatment of myofibrils on the activities of the tree types of proteinases 
Myofibrils in $0.5 \mathrm{M} \mathrm{NaCl}, 20 \mathrm{mM}$ Tris-HCl (pH 7.5) were incubated for $2 \mathrm{hr}$ at various $\mathrm{pH}$ in ice bath and neutralized. Activities of three types of proteinases were assayed at $\mathrm{pH} 7$ by using treated myofibrils. Other conditions were the same as in Fig. 2. The same symbols as in Fig. 2 were also used. 
Fig. 1.

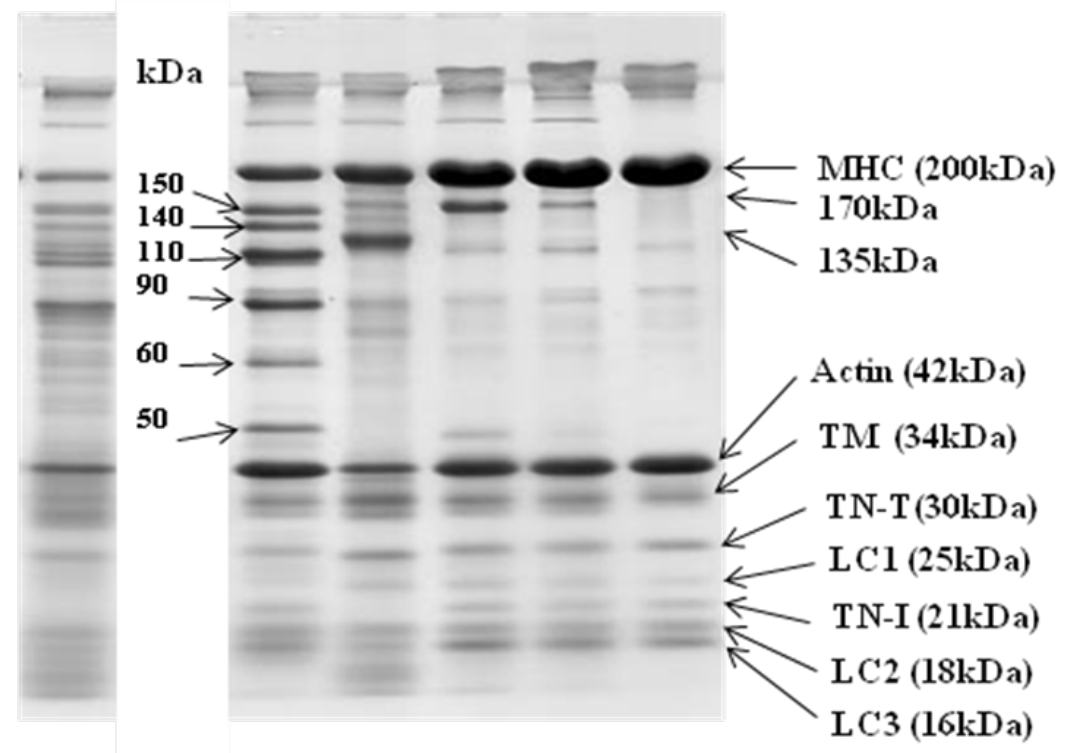

(a)

$\begin{array}{llll}\text { (b) } & \text { (c) } & \text { (d) } & \text { (e) }\end{array}$

Fig. 2.

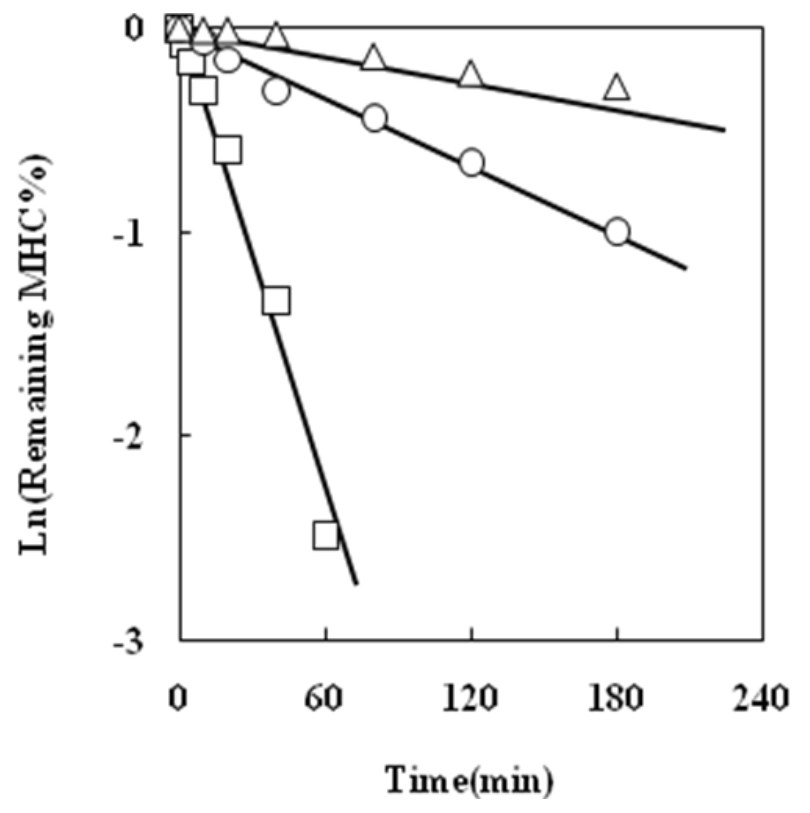


Fig. 3.

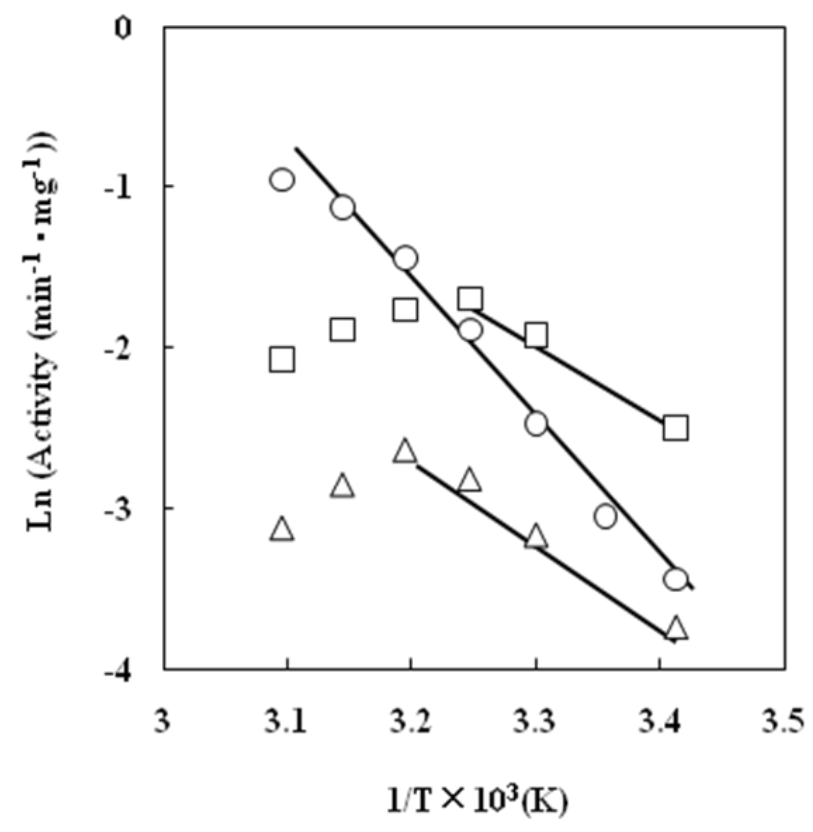

Fig. 4.

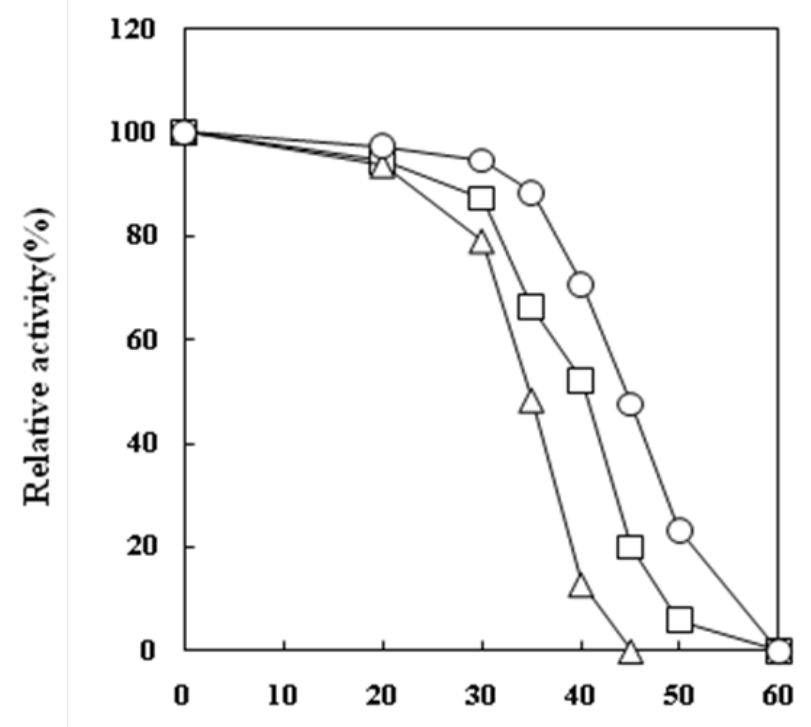

Heating temp er ature $\left({ }^{\circ} \mathrm{C}\right)$ 
Fig. 5.

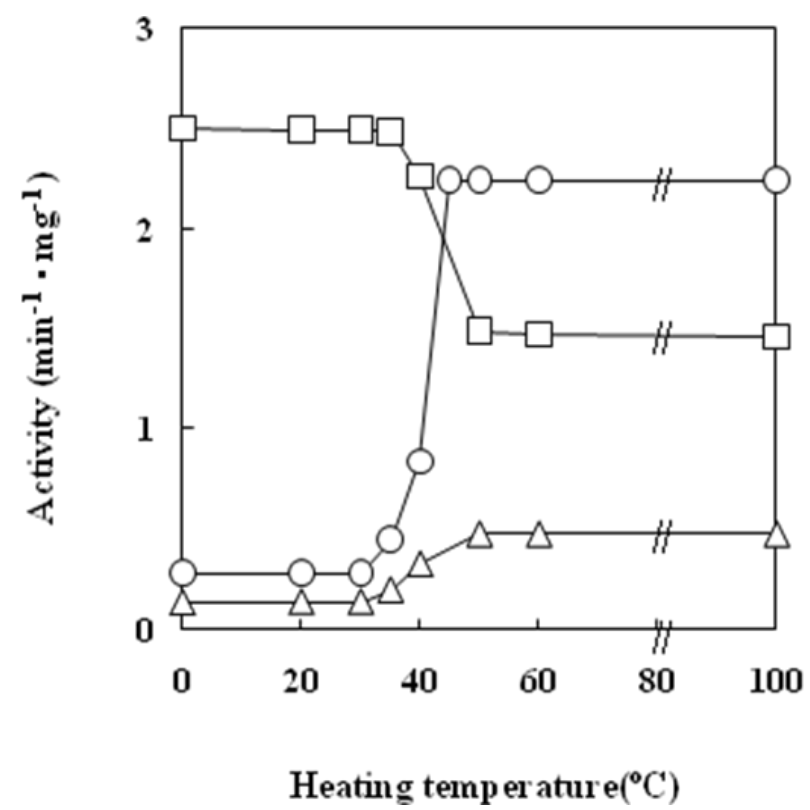

Fig.6.

(a)

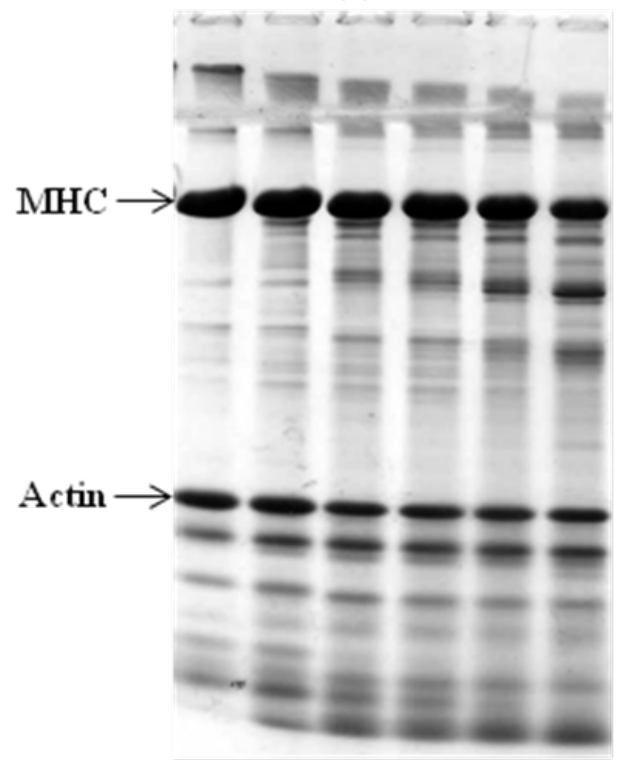

(b)
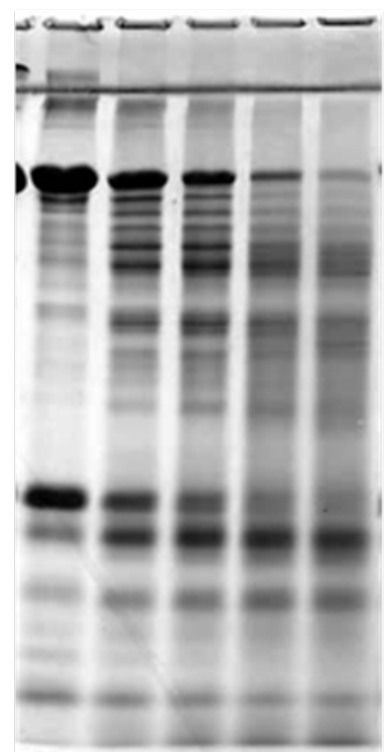

$\begin{array}{llllll}\text { Mf } & 0 & 10 & 20 & 40 & 60\end{array}$ $\begin{array}{lllll}0 & 10 & 20 & 40 & 60\end{array}$

Digestion (time) 
Fig. 7.

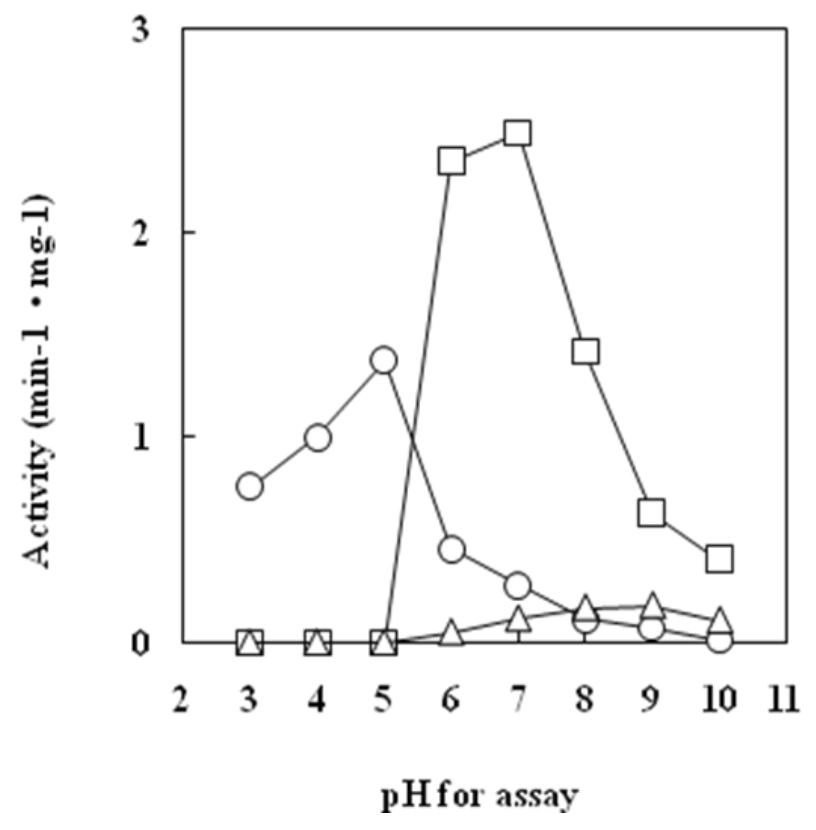

Fig. 8.

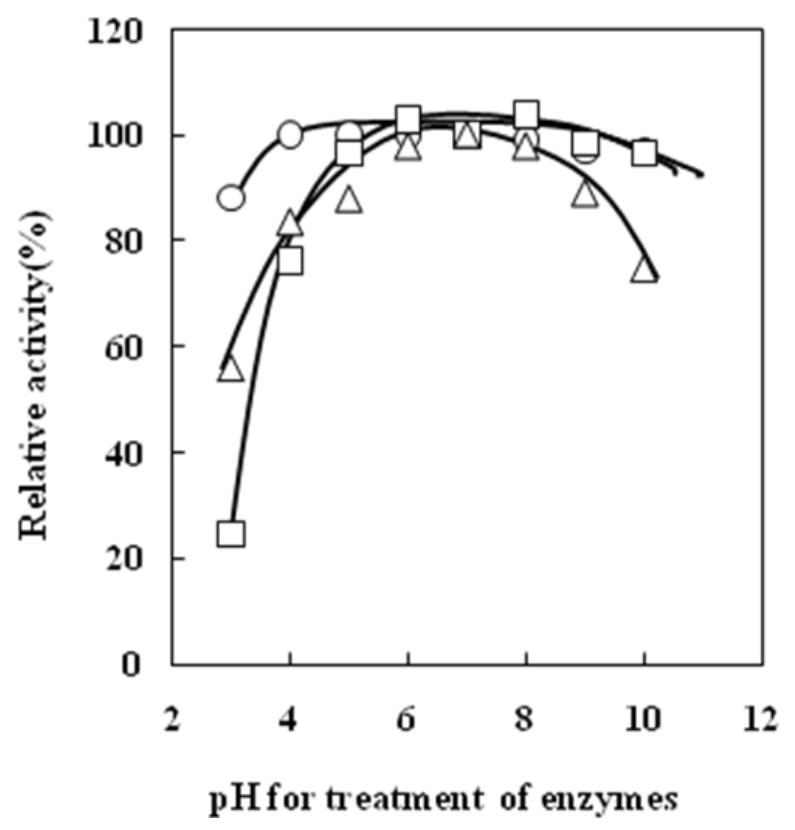


Fig. 9.

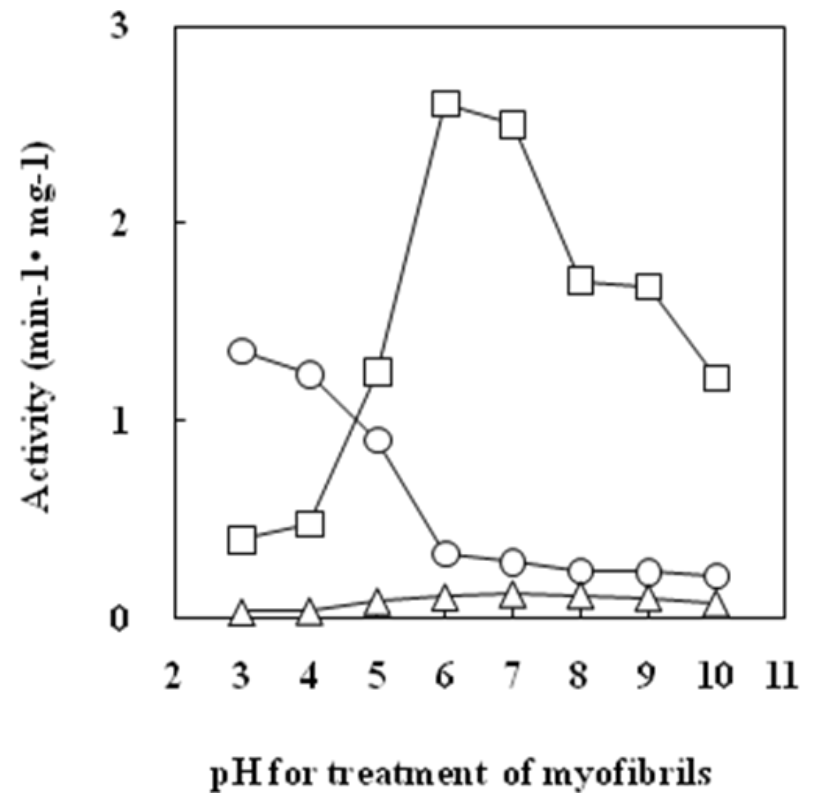

